\title{
CAPTURADOS PELA INCERTEZA: AS LIÇÕES DO CASO DA “PÍLULA DO CÂNCER" PARA A PRECAUÇÃO
}

\author{
CAUGHT BY UNCERTAINTY: THE LESSONS FROM THE "CANCER PILL" CASE \\ FOR A PRECAUTION
}

\begin{abstract}
ATRAPADOS POR LA INCERTIDUMBRE: LAS LECCIONES DEL CASO DE LA "PÍLDORA DEL CÁNCER" PARA LE PRECAUCIÓN
\end{abstract}

\begin{abstract}
ARLENE ANÉLIA RENK
http:// orcid.org/0000-0001-5029-7066 / http://lattes.cnpq.br/2616118903127201 / patricia_jung@outlook.com

Professora do Programa de Pós-graduação Stricto Sensu em Direito na Universidade Comunitária da Região de Chapecó. Doutora e Mestre em Antropologia pelo Museu Nacional, Universidade Federal do Rio de Janeiro.

Chapecó, SC, Brasil.

PATRICIA JUNG

http://orcid.org/0000-0001-5029-7066 / http://lattes.cnpq.br/2616118903127201 / patricia_jung@outlook.com Mestranda no Programa de Pós-graduação Stricto Sensu em Direito da Universidade Comunitária da Região de Chapecó.

Chapecó, SC, Brasil.
\end{abstract}

\section{RESUMO}

A fosfoetanolamina sintética, conhecida popularmente como "pílula do câncer" se torna um campo de análise empírica pelas controvérsias sobre a liberação desta substância como medicamento. Frente a incerteza científica sobre sua eficácia e segurança vários foram os posicionamentos tomados, ora irregularmente distribuída, ora questionada judicialmente, ora liberada por lei e novamente suspensa. Em cenários de incerteza como este, que desembocam na ciência do Direito, o princípio da precaução ampara o processo decisório. Diante disso, se objetiva compreender como o caso da substância em apreço, elucida a problemática advinda da concentração em instrumentos de gestão sobre a precaução que mantém inoperativos esquemas de governança. A pesquisa é amparada pelo método dedutivo, sendo empregadas a pesquisa bibliográfica e documental, conjugada com o estudo de caso. Neste percurso, se verificou o quão ambígua e conturbada a arena decisória pode se revelar sem que haja o estabelecimento de parâmetros precaucionais orientados por um processo de governança.

Palavras-chave: Fosfoetanolamina; Gestão; Governança; Precaução.

\section{ABSTRACT}

Synthetic phosphoethanolamine, popularly known as the "cancer pill", becomes a field of empirical analysis for the controversies over the release of this substance as a drug. Faced with scientific uncertainty about its effectiveness and security several were the positions taken, times irregularly distributed, times challenged judicially, and times released by law and again suspended. In scenarios of uncertainty such as this, which lead to the science of law, the precautionary principle supports the decision-making process. In view of this, it is intended to understand how the case of the substance in question, elucidates the problem of concentration in management tools on the precaution that maintains inoperative governance schemes. The research is supported by the deductive method, being used the bibliographical and documentary research, combined with the case study. In this course, it was verified how ambiguous and troubled the decision-making arena can be without the establishment of precautionary parameters guided by a governance process.

Keywords: Phosphoethanolamine; Management; Governance; Precaution. 


\section{RESUMEN}

La fosfoetanolamina sintética, conocida popularmente como "píldora del cáncer", se convierte en un campo de análisis empírico por las controversias sobre la liberación de esta sustancia como medicamento. Frente a la incertidumbre científica sobre su eficacia y seguridad varios fueron los posicionamientos tomados, ya sea irregularmente distribuida o cuestionada judicialmente, ya sea liberada por ley o nuevamente suspendida. En escenarios de incertidumbre como este, que desembocan en la ciencia del Derecho, el principio de la precaución ampara el proceso decisorio. Ante ello, se pretende comprender cómo el caso de la sustancia en cuestión, elucida la problemática proveniente de la concentración en instrumentos de gestión sobre la precaución que mantiene inoperativos esquemas de gobernanza. La investigación es amparada por el método deductivo, siendo empleadas la investigación bibliográfica y documental, conjugada con el estudio de caso. En este recorrido, se comprobó lo ambigua y conturbada que la arena decisoria puede revelarse sin que haya el establecimiento de parámetros cautelares orientados por un proceso de gobernanza.

Palabras clave: Fosfoetanolamina; Gestión; Gobernanza; Precaución.

\section{SUMÁRIO}

INTRODUÇAO; 1 A FOSFOETANOLAMINA COMO OBJETO DE ESTUDO; 2 POR QUE CHAMAR A PRECAUÇÃO A ATUAR NO CASO DA FOSFOETANOLAMINA?; 3 OS DESDOBRAMENTOS PRECAUCIONAIS DO CASO FOSFOETANOLAMINA: GESTÃO E GOVERNANÇA; CONCLUSÃO; REFERÊNCIAS.

\section{INTRODUÇÃO}

O caso da "pílula do câncer" representa mais um dos momentos em que a incerteza científica embaça o poder decisório e colabora para que decisões arbitrárias sejam tomadas nas diversas esferas de poder na qual se circunscreve determinada incerteza. No campo jurídico, com a finalidade de evitar-se a paralisia, a incerteza cientifica é mediada pelo princípio da precaução. Ainda que controverso, através dele apregoa-se que medidas protetivas devem ser tomadas de modo proativo, ao invés de aguardarmos por medidas reativas à inação.

$\mathrm{Na}$ saúde, a incerteza científica sobre a liberação de um medicamento é ainda mais prudente, considerando que se coloca em xeque o maior bem jurídico, a vida. Contudo, ao mesmo tempo que se concebe como uma ameaça, representa a esperança de cura, como consequência a ambiguidade de posicionamentos na arena de decisões é inevitável, tendo sido até o momento prolatadas decisões que atendem as mais diversas demandas sem que haja um posicionamento definitivo sobre a matéria.

Sem tomar partido sobre a aplicabilidade do princípio da precaução, assim como da liberação da fosfoetanolamina, o que se pretende com este texto é compreender como o caso da substância em apreço elucida a problemática advinda da concentração em instrumentos de gestão sobre a precaução que mantém inoperativos esquemas de governança, acarretando difusão nas decisões jurídicas, políticas e sanitárias, assim como no posicionamento popular. 
A via metodológica adotada é a do método dedutivo, empregando-se as técnicas de pesquisa bibliográfica e documental conjugada com o estudo de caso, a fim de conferir a lógica interna necessária entre os elementos em apreço.

Inicialmente, é evidenciando como a fosfoetanolamina se inseriu no panorama sanitário nacional, assinalando as implicações decorrentes da sua distribuição, liberação e suspensão. Em seguida entrelaça-se a precaução com o caso da fosfoetanolamina, analisando como este princípio poderia ter orientado o processo de avaliação de liberação da substância, e sendo assim, as controvérsias que decorrem por ter sido rechaçado. Enfim, ao compreender a governança como instrumento para tomada de decisões e criação de políticas públicas, são esboçadas suas características no âmbito na precaução e suas intercorrências no caso da fosfoetanolamina.

Tal análise revela sua importância à Ciência do Direito, à medida que impõe a ela a solução, pacificação e regulamentação de situações como a da fosfoetanolamina. Ainda que estranhas ao Direito, permanece a imperatividade de que sejam estabelecidos parâmetros à decisão efetiva, sem que seja necessário se render a outras áreas especialistas nas questões em apreço, em especial a técnica, conforme Pardo ${ }^{1}$ alertara.

\section{A FOSFOETANOLAMINA COMO OBJETO DE ESTUDO}

A fosfoetanolamina, desde 2014, tem alcançado os holofotes por capitanear a discussão sobre a distribuição de novos medicamentos sem comprovação testada, em pacientes terminais ou gravemente debilitados em decorrência de câncer².

A fosfoetanolamina (FOS) foi sintetizada ainda em 1990, pelo bioquímico e pesquisador Gilberto Chierice, no Instituto de Química de São Carlos, da Universidade de São Paulo. Desde então, o pesquisador, além de produzir a substância, tem promovido sua distribuição. Após estudos pré-clínicos favoráveis, de forma independente, Chierice encapsulou a FOS e a distribuiu

\footnotetext{
1 PARDO, José Esteve. 0 desconcerto do Leviatã: política e direito perante as incertezas da ciência. São Paulo: Inst. O Direito por um Planeta Verde, 2015. 3 v. (Direito ambiental para o século XXI).

2 TEODORO, Cristiane Roberta dos Santos; CAETANO, Rosângela. 0 caso da fosfoetanolamina sintética e a preocupante flexibilização das normas sanitárias no Brasil. Physis Revista de Saúde Coletiva, Rio de Janeiro, v. 26, n. 3, p. 741-746, 2016. Disponível em: < http://www.scielo.br/scielo.php?script=sci_arttext\&pid=S0103-73312016000300741>. Acesso em: 20 abr. 2017.
} 
para pacientes voluntários com diferentes tipos de neoplasias (câncer) ${ }^{3}$ - atitude não sancionada com legitimidade pelos pares no mundo científico, pela não usualidade das regras do campo ${ }^{4}$. Tal foi sua repercussão que teve anúncio como a "pílula de cura do câncer"5.

Contudo, apenas em 2014 tornaram-se públicas tais atividades. Nesse ano, após a aposentadoria compulsória do pesquisador, a instituição passou a proibir a distribuição e produção de qualquer droga sem registro, situação na qual se encontrava a fosfoetanolamina sintética ${ }^{6}$. A questão repercutiu nacionalmente, com a reivindicação dos indivíduos até então submetidos - clandestinamente conforme preceitos dos órgãos de vigilância e reguladores - ao tratamento, havendo a judicialização de diversas demandas que tinham por finalidade garantir a distribuição do medicamento pela USP.

As controvérsias sobre a FOS incidem sobre o fato de a substância ter sido distribuída sem a realização do protocolo necessário, padecendo assim da autorização da Agência Nacional de Vigilância Sanitária (Anvisa) ${ }^{7}$; logo, tendo sido irregularmente produzida e experimentada. Agrava-se a situação por sua distribuição não ter sido acompanhada de monitoramento de eficácia e quanto à existência de efeitos colaterais ${ }^{8}$.

O fato é que a FOS, ao ter sido distribuída sem qualquer regulação, nem mesmo como substância em fase de testes, desrespeitou os procedimentos científicos necessários para sua liberação e as determinações presentes na Lei n. 6.360/76, na qual são estabelecidas como

${ }^{3}$ CANSIAN, Natalia; WATANABE, Phillippe; LOPES, Reinaldo José. "Pílula do Câncer" vira suplemento, e Anvisa investigará se há infração. Folha de São Paulo, 2017. Disponível em: < http://www1.folha.uol.com.br/equilibrioesaude/2017/02/1859504-pilula-do-cancer-vira-suplemento-eanvisa-investigara-se-ha-infracao.shtml>. Acesso em: 16 maio 2017.

${ }^{4}$ BOURDIEU, Pierre. O Campo científico. In: ORTIZ, Renato. Bourdieu: Sociologia. São Paulo: Ática, 1983, p. $122-155$.

${ }^{5}$ RÊGO, Juliana Florinda M.; LOPES, Gilberto; RIECHELMANN, Rachel P.; STENBERG, Cinthya; FERRARI, Claudio; FERNANDES, Gustavo. A "miracle" câncer drug in the era of social media: a survey of Brazilian oncologists' opinions and experience with phosphoethnolamine. Rev. Assoc. Med. Bras., São Paulo, v. 63, n. 1, p. 70-77, 2017.Disponível em: <http://www.scielo.br/scielo.php?script=sci_arttext\&pid=S010442302017000100070>. Acesso em 05 abr. 2017

${ }^{6}$ CANSIAN, Natalia; WATANABE, Phillippe; LOPES, Reinaldo José. "Pílula do Câncer" vira suplemento, e Anvisa investigará se há infração. Folha de São Paulo, 2017. Disponível em: < http://www1.folha.uol.com.br/equilibrioesaude/2017/02/1859504-pilula-do-cancer-vira-suplemento-eanvisa-investigara-se-ha-infracao.shtml>. Acesso em: 16 maio 2017.

${ }^{7}$ A Anvisa, foi instituída pela Lei n. 9.782/1999, atribuindo-lhe como finalidade a promoção da saúde da população, através do exercício do controle sanitário da produção e consumo de produtos e serviços submetidos ao registro no órgão. BRASIL. Agência Nacional de Vigilância Sanitária. Institucional. 2017a.Disponível em: <http://portal.anvisa.gov.br/institucional>. Acesso em 20 jun. 2017.

${ }^{8}$ CANSIAN, Natalia; WATANABE, Phillippe; LOPES, Reinaldo José. Op. cit. 
requisitos para utilização e comercialização de medicamentos comprovações científicas quanto a sua segurança, qualidade e eficácia9.

Importante esclarecer que se poderia argumentar a legalidade da distribuição através da RDC n. $38 / 2013^{10}$, ao caracterizar o tratamento como programa de uso compassivo. Esse programa envolve a distribuição de medicamentos, independentemente da fase de estudos clínicos nos quais se encontram, desde que destinados a pacientes com enfermidades graves ou que tenham a vida ameaçada, e para os quais não haja alternativa terapêutica satisfatória em medicamentos registrados no País. No entanto, ainda haveria a necessidade de anuência da Anvisa mediante a apresentação de informações de segurança e eficácia, requisitos não preenchidos para distribuição da FOS.

Se no campo científico a tomada de posição do pesquisador Chierice esteve mais próxima do herético, preocupando-se, ao que se pode observar, com o suposto resultado e acesso à FOS por parte dos usuários em potencial, é na esfera da vigilância, campo externo, que o cerceamento e a coerção serão exercidos com a força de violência legítima que cabe ao Estado, conforme apregoa Weber ${ }^{11}$. Nesse panorama, com base no direito à saúde, ou em inovações jurídicas como o right to try (direito de tentar) ou o direito à esperança, viu-se autorizado o fornecimento da FOS, evidenciando-se a fragilidade jurídica, regulatória e fiscalizatória no Brasil $^{12}$.

Os cuidados que a situação aspirava foram, naquele momento, negligenciados nas tomadas de decisões que se seguiram, tanto no Legislativo e Executivo quanto no Judiciário, vez que se encontrava em risco a saúde coletiva ao permitir-se que indivíduos se submetessem à

\footnotetext{
${ }^{9}$ BRASIL. Lei n. 6.360, de 23 de setembro de 1976. Dispõe sobre a vigilância sanitária a que ficam sujeitos os medicamentos, as drogas, os insumos farmacêuticos e correlatos, cosméticos, saneantes e outros produtos, e dá outras providências. In: Diário Oficial da República Federativa do Brasil, Brasília, DF, 24 set. 1976. Disponível em: <http://www.planalto.gov.br/ccivil_03/leis/l6360.htm>. Acesso em: 15 abr. 2016.

${ }^{10}$ BRASIL. Agência Nacional de Vigilância Sanitária. Resolução n. 38, de 12 de agosto de 2013. Aprova o regulamento para os programas de acesso expandido, uso compassivo e fornecimento de medicamento pós-estudo. Disponível em: http://bvsms.saude.gov.br/bvs/saudelegis/anvisa/2013/rdc0038_12_08_2013.html>. Acesso em 20 abr. 2017.

11 WEBER, Max. Economia e Sociedade. V. 1. Brasília: UNB, 2004.

12 BARBOSA, Elina Magnan. Right to try? Fosfoetanolamina, di Bella e Stamina: uma análise ítalo-brasileira. Revista de Direito Sanitário, São Paulo, v. 17, n. 2, p. 66-92, jul./out. 2016. Disponível em: < http://www.revistas.usp.br/rdisan/article/view/122307>. Acesso em: 20 abr. 2017.
} 
incerteza de um tratamento experimental ilegal. O direito seria legítimo desde que se respeitassem os protocolos estabelecidos, a ética e a saúde pública ${ }^{13}$

Barbosa $^{14}$ defende que decisões judiciais que aceitam terapias experimentais como uma obrigação estatal de custear, cometem o erro tanto de confundir a liberdade de cura, quanto o de confundir tratamentos baseados em evidências com aqueles baseados em ilusão. Desprestigiase também o demandante com o direito de ser informado com a verdade, violando ainda a obrigação moral do médico em oferecer o melhor e mais eficaz tratamento, não o submetendo a riscos inúteis.

A fim de atender a comoção nacional incidente sobre a substância, como medida emergencial e viabilizadora desta, ao final de 2015, o Ministério da Ciência, Tecnologia, Inovação e Comunicações (MCTIC) anunciou investimentos de R\$ 10 milhões de reais em pesquisas no período de três anos ${ }^{15}$. Os resultados preliminares corroboraram no sentido de invalidação de ensaios clínicos em humanos e da restrição ao registro sanitário. No mesmo caminho emergencial, para pôr fim às controvérsias, o Congresso Nacional apresentou a Lei $\mathrm{n}$. 13.269/16, sancionada pela presidente Dilma Rousseff, autorizando a administração de FOS em pacientes com neoplasia maligna ${ }^{16}$. A lei autorizava, dentre outras ações, a produção, importação, distribuição e prescrição da FOS.

Cabe registrar que a Anvisa, como órgão competente e regulador do controle sanitário de medicamentos, e que resguarda a saúde pública através de parâmetros internacionais a fim de garantir que as exigências técnico-científicas estejam dentro dos parâmetros éticos, foi desfavorável à liberação da FOS nas circunstâncias nas quais estava sendo distribuída. A interferência dos poderes Legislativo, Executivo e Judiciário na competência técnico-sanitária da Anvisa, como lembram Teodoro e Caetano ${ }^{17}$, representou uma grave ameaça ao seu papel na regulação e proteção da saúde pública.

13 TEODORO, Cristiane Roberta dos Santos; CAETANO, Rosângela. Op. Cit.

${ }^{14}$ BARBOSA, Elina Magnan. Op. Cit.

15 BRASIL. Ministério da Ciência, Tecnologia, Inovações e Comunicações. MCTI anuncia plano de trabalho para as pesquisas sobre a fosfoetanolamina. 2015. Disponível em: <http://www.mctic.gov.br/mctic/opencms/salalmprensa/noticias/arquivos/migracao/2015/11/MCTI_anu ncia_plano_de_trabalho_para_as_pesquisas_sobre_a_fosfoetanolamina.html>. Acesso em 25 abr. 2017. ${ }_{16}$ BRASIL. Lei n. 13.269, de 13 de abril de 2016. Autoriza o uso da fosfoetanolamina sintética por pacientes diagnosticados com neoplasia maligna. In: Diário Oficial da República Federativa do Brasil, Brasília, DF, 14 abr. 2016a. Disponível em: <http://www.planalto.gov.br/ccivil_03/_Ato20152018/2016/Lei/L13269.htm>. Acesso em: 15 abr. 2016.

17 TEODORO, Cristiane Roberta dos Santos; CAETANO, Rosângela. O caso da fosfoetanolamina sintética e a preocupante flexibilização das normas sanitárias no Brasil. Physis Revista de Saúde Coletiva, Rio de Janeiro, v. 26, n. 3, p. 741-746, 2016. Disponível em: < 
Com a promulgação da referida lei, em maio de 2016, foi deferida ação direta de inconstitucionalidade n. 5.501, protocolada pela Associação Médica Brasileira, restando suspensa a lei até o julgamento da matéria. Igualmente foram suspensas decisões judiciais de obrigação de fornecimento da FOS por parte do governo. Mais recentemente, o Duelo a garrotazos ${ }^{18}$ sobre a matéria tem versado sobre o fornecimento de fosfoetanolamina como suplemento alimentar, novamente sem registro na Anvisa, produzido na Flórida, Estados Unidos, e desde 16 de março deste ano liberada para importação para consumo individual.

Nesse sentido, a FOS constitui-se como objeto de estudo à medida que as controvérsias postas possuem como pano de fundo a incerteza científica sobre a substância, matéria da qual o princípio da precaução se apropria na tomada de decisão jurídica.

\section{POR QUE CHAMAR A PRECAUÇÃO A ATUAR NO CASO DA FOSFOETANOLAMINA?}

Juridicamente, avaliar o caso da fosfoetanolamina perpassa impreterivelmente pelo princípio da precaução. Nosso objetivo nesta seção é demonstrar tais motivações, e como este princípio foi administrado nos desfechos do caso. Logo, não há a pretensão de perpassar as críticas acerca da inaplicabilidade desse princípio, como aquelas apontadas por Gomes ${ }^{19}$ e mais incisivamente por Sustein, ${ }^{20}$ vez que consideramos já estarmos diante de um instituto jurídico com corpo acadêmico, doutrinário e jurisprudencial; sendo assim, em vez de continuarmos a digladiar, propomos avaliar por quais vias caminhar de modo mais seguro.

http://www.scielo.br/scielo.php?script=sci_arttext\&pid=S0103-73312016000300741>. Acesso em: 20 abr. 2017.

${ }^{18}$ Quadro de Francisco de Goya de 1823 que retrata dois lutadores, cada um com seu respectivo bastão, envoltos em um pântano. Ao apreciá-lo, podemos nos perguntar "quem vai ganhar?" Apostamos em um ou em outro, sem nos darmos conta de que existe a possibilidade de nenhum deles vencer diante do pântano. Nesse sentido, enquanto os debates sobre a liberação da fosfoetanolamina perduram sem que haja uma decisão definitiva regulamentando a substância, parece-nos que o pântano formado pelos debates pode consumir os bens jurídicos em jogo em um continuum de tentativas viabilizadoras do tipo "a qualquer custo".

19 GOMES, Carla Amado. Risco e Modificação do Acto Autorizativo Concretizador de Deveres de Protecção do Ambiente. 2007. 566 f. Tese (Doutorado em Direito Administrativo) - Universidade de Lisboa, Lisboa, 2007.

20 SUSTEIN, Cass R. Para além do princípio da precaução. Revista de Direito Administrativo, Rio de Janeiro, v. 259, p. 11-71, abr. 2012. Trimestral. Disponível em: < http://bibliotecadigital.fgv.br/ojs/index.php/rda/article/view/8629>. Acesso em: 5 out. 2016. 
A precaução nasce como uma "margem de segurança suplementar"21 ao princípio da prevenção, sendo chamada a atuar em situações de riscos e incertezas científicas. Destina-se a eliminar riscos hipotéticos ou potenciais, isto é, aqueles que, embora pressentidos, não são comprovados. Logo, o limite da previsibilidade decorrente da finitude do conhecimento humano, é o input para sua atuação. ${ }^{22}$ Traduz-se em ações proativas e preventivas em relação a um possível dano, a fim de evitar o laissez-faire diante da incerteza.

Isso significa que, a partir da precaução, encaminha-se para um período de transição de uma regulação preventiva, fundada na exigência de provas científicas, com posterior regulação de um produto ou atividade, para uma regulação precaucional que exige a regulação de riscos hipotéticos, evitando que as divergências científicas sejam empregadas como escusa para inação ${ }^{23}$. Importante frisar que, ao contrário da prevenção, invocar a precaução dispensa a necessidade de provas sobre a existência de um risco concreto ou um perigo, mas requer a evidência de incerteza científica sobre as ameaças e danos sérios e irreversíveis ${ }^{24}$.

A imprevisibilidade inerente à precaução e a consequente relação com o risco residem em a) verificar a ocorrência de fenômeno indesejável; b) se ocorrer o fenômeno, em que momento ele ocorrerá; nesta hipótese, c) quais os desencadeamentos desse fenômeno ${ }^{25}$. Em outras vias, pode-se articular que a precaução “[...] consiste em ponderar um risco mal definido, mal conhecido ou conhecido mas difícil de quantificar [...]"26; são situações de “indeterminação, ambiguidade ou ignorância"27. Por isso, quando se trata da precaução, entra em jogo a probabilidade de ocorrência de determinado evento e seu correspondente potencial lesivo.

Através da precaução, impõe-se que a incerteza deixe de ser uma fatalidade e adentre no campo da ponderação decisória, conforme Gomes ${ }^{28}$ assinala. Na prática, como refere a autora, um dos maiores problemas relacionados à precaução se encontra na interpretação do seu alcance, vez que ora pode-se estar aquém do limiar de previsibilidade, ora pode-se estar além.

${ }^{21}$ GOMES, Carla Amado. Op. cit., p. 169.

22 Idem

${ }^{23}$ ARAGÃO, Alexandra. Princípio da precaução: manual de instruções. Revista do Centro de Estudos de Direito do Ordenamento, do Urbanismo e do Ambiente, Coimbra, n. 22, p. 9-57, 2008. Disponível em: < https://digitalis.uc.pt/pt-pt/node/106201?hdl=8833>. Acesso em: 5 out. 2016.

24 BERGER FILHO, Aírton Guilherme. A governança dos riscos das nanotecnologias e o princípio da precaução: um estudo a partir da teoria dialética da rede. 2016. 438 f. Tese (Doutorado em Direito) Universidade do Vale do Rio dos Sinos, São Leopoldo, 2016.

${ }^{25}$ ARAGÃO, Alexandra. Op. cit.

${ }^{26}$ GOMES, Carla Amado. Op. cit., p. 169

${ }^{27}$ BERGER FILHO, Aírton Guilherme. Op. cit., p. 324.

${ }^{28}$ GOMES, Carla Amado. Op. cit. 
Não obstante, o problema se reveste em compreender qual o limiar máximo de probabilidade de ocorrência de uma atividade que provoque efeitos lesivos para que a prevenção seja chamada a atuar, e a partir de qual patamar mínimo seria possível limitar para que a precaução incorra sobre o caso.

Nesse sentido, o cuidado a se tomar estará relacionado a não tornar a insegurança do risco um meio para posicionar a segurança ambiental e sanitária acima de qualquer outro objetivo. A fim de que não seja justificação para paralisia, a insegurança é mais um fator a ser gerido do que eliminado, evitando-se que em um Estado de Direito Democrático seja invocado o in dubio pro securitate em detrimento do in dubio pro libertate.

Entendemos que o caso da fosfoetanolamina encontra-se revestido por essa problemática, assim como se encontram outros casos menos midiáticos, e até mesmo em outros campos científicos, como os licenciamentos ambientais do qual a Hidrelétrica de Barra Grande é exemplo emblemático. Semelhante é o entendimento do Ministro Luís Roberto Barroso no julgamento da cautelar da ADI 5.501, de relatoria do Ministro Marco Aurélio, no qual aponta que, mediante a incerteza científica sobre os efeitos de uma substância como a fosfoetanolamina, em prol da segurança, a solução estará no incentivo aos estudos científicos, testes e protocolos, jamais na sua liberação para o consumo.

Se considerarmos que nos Estados Unidos apenas um em cada dez medicamentos que ultrapassam a primeira fase de ensaios clínicos chega a ser autorizado pelo órgão competente, é espantoso acreditar que no Brasil a FOS tenha sido legalizada às pressas e à revelia de qualquer procedimento legal estabelecido, tomando como base somente publicações e testes em laboratórios e animais. Ademais, o ambiente universitário em que a substância foi produzida e irregularmente testada sequer é uma planta farmacêutica, muito menos uma farmácia ambientes que atendem normas de segurança e qualidade ${ }^{29}$.

Do mesmo modo, Alves, Delduque e $\operatorname{Santos}^{30}$ alertam para como a aprovação da referida Lei n. 13.269/16 colabora para a desorganização do sistema regulatório de saúde nacional, colocando em cheque a legislação em vigor com base em uma inovação jurídica sem segurança científica, vez que carece de comprovação de qualidade, segurança e eficácia. Cumpre notar

\footnotetext{
29 NATURE. Drugs on demand: controversy in Brazil over access to a purported cancer cure could set a harmful precedent. Nature, v. 527, p. 410, 2015. Disponível em: < https://www.nature.com/news/drugson-demand-1.18873>. Acesso em 27 abr. 2018.

${ }^{30}$ ALVES, Sandra Mara Campos; DELDUQUE, Maria Célia; SANTOS, Alethele Oliveira. Lei n.-13.269/2016: a comoção da sociedade vence o método científico. Cadernos de Saúde Pública, Rio de Janeiro, v. 32, n. 6, p. 1-2, 2016. Disponível em: <http://www.scielo.br/pdf/csp/v32n6/1678-4464-csp-32-06-e00070116.pdf>. Acesso em: 01 abr. 2017.
} 
que a criação dessa lei atendeu um papel populista importante, especialmente pelo fato de a sanção ter ocorrido durante o processo de impeachment da presidente então em exercício.

Tal populismo também se verifica através da análise da exposição de motivos do projeto de lei n. 3.454/2015 que a originou, em que foram tomados como argumentos de justificação: a) entrevista (e não publicações científicas) de Gilberto Chierice ao portal de notícias G1 sobre o potencial da FOS, aliada aos depoimentos positivos colhidos dos sujeitos submetidos sem qualquer controle ao tratamento; b) o entendimento jurisprudencial do qual é precursor o Ministro Edson Fachin (conforme já exposto), apontando a liberação da FOS para portadores de neoplasia em condição de terapia paliativa; c) a suposta viabilidade decorrente do interesse apresentado pela Fundação Oswaldo Cruz na patente da substância, o que colocaria os interesses da indústria farmacêutica em primeiro lugar ${ }^{31}$.

Note-se que, com base nesses elementos, sem qualquer fundamento sólido, firmou-se a justificativa de que a lei seria de relevância pública. Como apontaram Alves, Delduque e Santos $^{32}$, sancionar uma lei nos termos realizados, para atender exclusivamente a comoção social, representa retrocesso ao período das trevas, no qual as decisões eram tomadas como base em dogmas e fé.

Cabe, ainda, apontar que o percurso jurídico da FOS pode criar riscos de uma suposta jurisprudência favorável no futuro para a liberação de medicamentos não aprovados no País. Lições semelhantes são colacionadas pelo caso Laetrile, em 1970, nos Estados Unidos, no qual a Corte não reconheceu a obrigação do Estado de fornecer a todos tratamento experimental, entendendo que mesmo pacientes com doenças terminais somente poderiam ser submetidos a esses tratamentos mediante o preenchimento de requisitos científicos aprovados pelo órgão competente; assim também os casos di Bella (1997-1998) e Stamina (2011-2015), em que a Corte italiana, em um primeiro momento, concedeu o direito, mas mudou sua orientação no sentido da não obrigação estatal em fornecer tratamento experimental ${ }^{33}$.

Ainda nos Estados Unidos, em alguns estados nos quais houve a liberação legal para que indivíduos experimentem medicamentos fora do registro como um meio de favorecimento ao direito de tentar, as leis permissivas dessa prática ascenderam os debates por oferecer falsas

\footnotetext{
${ }^{31}$ BRASIL. Câmara dos Deputados. Projeto de Lei n. ${ }^{\circ}$ 3.454, de 2015. Dispõe sobre a fabricação, produção e distribuição da Fosfoetanolamina Sintética aos pacientes com câncer. Disponível em: < http://www.camara.gov.br/sileg/integras/1410290.pdf>. Acesso em: 01 jun. 2017.

${ }_{32}$ ALVES, Sandra Mara Campos; DELDUQUE, Maria Célia; SANTOS, Alethele Oliveira. Op. cit.

${ }^{33}$ BARBOSA, Elina Magnan. Op. cit.
} 
esperanças em detrimento de vias mais promissoras de tratamento ${ }^{34}$, caminho no qual o Brasil deve seguir a partir da experiência da FOS.

Teodoro e Caetano ${ }^{35}$ ainda alertam que casos semelhantes ao da FOS podem acarretar na aceleração do desenvolvimento de medicamentos objetivando à concessão de registro sanitário no País, originando implicações:

i) multiplicidade de ensaios clínicos aprovados com resultados tendenciosos e baseados em evidências mais fracas e períodos de tempo menores; (ii) lacunas de informações fidedignas sobre a utilização e riscos dos medicamentos envolvidos; (iii) a simples disponibilização de novas terapias sem garantias de melhorias reais da saúde e da qualidade de vida, podendo levar ao agravamento dos quadros de doença; e (iv) geração de custos desnecessários aos sistemas de saúde.

A flexibilização elucidada pela FOS traz à tona a falta de garantia de ganhos à saúde, expõe este frágil bem a danos irreparáveis. Conforme reiteram Alves, Delduque e Santos ${ }^{36}$, as etapas que compreendem a concessão de registro não são apenas um requisito técnicoadministrativo, mas uma questão de saúde pública. Através do procedimento estabelecido, há a garantia de que medicamentos de qualidade estão sendo disponibilizados, de modo que o Estado atesta a sua segurança e se responsabiliza pela comercialização e consumo do medicamento. Barbosa $^{37}$ defende que não existe direito à saúde afastando as normas técnicas sanitárias, caso contrário estar-se-ia apenas diante do direito à liberdade individual de se submeter a essas terapias.

Por outro lado, a lei ainda possui como desdobrando o fato de que, por não ter seguido o protocolo vigente, são incertos os parâmetros a serem empregados na fiscalização de sua produção e distribuição. No mesmo sentido, Barbosa ${ }^{38}$ elenca duas considerações importantes sobre a distribuição da fosfoetanolamina: o limite a ser estabelecido e resgatado na relação de obrigação do Sistema Único de Saúde (SUS) e os serviços sanitários com seus pacientes ao condenar o Estado a fornecer gratuitamente tratamento experimental; e a futura responsabilização médica em prescrever o tratamento experimental sem que haja um protocolo a ser seguido, sem que haja conhecimento da dosagem e das contraindicações.

\footnotetext{
${ }^{34}$ NATURE. Op. cit.

35 TEODORO, Cristiane Roberta dos Santos; CAETANO, Rosângela. Op. cit.

${ }^{36}$ ALVES, Sandra Mara Campos; DELDUQUE, Maria Célia; SANTOS, Alethele Oliveira. Op. cit.

37 BARBOSA, Elina Magnan. Op. cit.

38 Ibidem.
} 
Apesar de serem incertezas nascidas nas mais diversas ciências, é no Direito que elas desembocam como um problema jurídico a ser mediado. As decisões hão de ser tomadas a partir da ciência do Direito e de seus instrumentos próprios, e não da suposta técnica leiga, apontada por Teodoro e Caetano ${ }^{39}$. Embora Barbosa ${ }^{40}$ aposte única e exclusivamente na técnica como meio insuperável para que os juízes atuem de modo mais isonômico e imparcial, vez que seria isenta de intenção e ideologias, esse é um entendimento ao qual não nos filiamos. Sendo assim, propomos que o risco deve ser mediado por critérios de racionalidade, os quais procura-se trazer à tona no presente artigo. Daí a necessidade de discutir questões de governança e gestão, para compreendermos os caminhos tortuosos pelo quais o caso da fosfoetanolamina foi submetido.

\section{OS DESDOBRAMENTOS PRECAUCIONAIS DO CASO FOSFOETANOLAMINA: GESTÃO E GOVERNANÇA}

Embora não se tenha avançado em uma teoria geral da governança, havendo contradições e imprecisões ${ }^{41}$, Berger Filho ${ }^{42}$ define-a como um processo de integração e coordenação de diferentes atores, com a finalidade de discutir coletivamente e atingir objetivos em um ambiente fragmentado e incerto. No âmbito nacional, e ainda mais no internacional, há uma multiplicidade de ordens normativas, que inclusive podem ser rivalizantes e sobrepostas. Neste diapasão, Kjaer ${ }^{43}$ entende que “[...] as estruturas de governança são terra de ninguém, onde as ordens normativas colidem e as batalhas de delineação destas ordens são levadas a cabo [...]".

\footnotetext{
39 TEODORO, Cristiane Roberta dos Santos; CAETANO, Rosângela. Op. cit.

40 BARBOSA, Elina Magnan. Op. cit.

41 KJAER, Poul F. La metamorfosis de la síntesis funcional: una perspectiva europeo-continental sobre governance, derecho y lo político en el espacio transnacional. Tradução Francisco Mujica. Wisconsin Law Review, $\quad$ p. 153-204, $2010 . \quad 2$ Disponível em: <http://www.academia.edu/2105401/La_metamorfosis_de_la_s\%C3\%ADntesis_funcional._Una_perspectiva europeo-continental_sobre_governance_derecho_y_lo_pol\%C3\%ADtico_en_el_espacio_trasnacional >.

Acesso em: 16 out. 2016.

42 BERGER FILHO, Aírton Guilherme. Op. cit.

43 "Las estructuras de governance son tierra de nadie, donde los órdenes normativos colisionan y las batallas de delineación de estosórdenes son llevadas a cabo." KJAER, Poul F. La metamorfosis de la síntesis funcional: una perspectiva europeo-continental sobre governance, derecho y lo político en el espacio transnacional. Tradução Francisco Mujica. Wisconsin Law Review, 2010, p. 156. Disponível em: <http://www.academia.edu/2105401/La_metamorfosis_de_la_s\%C3\%ADntesis_funcional._Una_perspectiva europeo-continental_sobre_governance_derecho_y_lo_pol\%C3\%ADtico_en_el_espacio_trasnacional >. Acesso em: 16 out. 2016.
} 
Traduz-se, assim, a governança como uma arena de conflitos, na qual se visa à administração conjunta de parâmetros para diferentes atores, gerando consensos operativos. Em função disso, pode-se determinar que a governança está orientada para questões como estas: quais são as estruturas, os atores envolvidos? Qual a função deles? Qual o conflito existente? Qual a hierarquia existente? Como compatibilizá-los e torná-los coerentes?

Ao transpor a governança para o cenário precaucional, estamos a tratar da governança de riscos, que, de acordo com Berger Filho, ${ }^{44}$ envolve a tomada de decisões em relação ao risco, assumindo como base os âmbitos em que o risco é avaliado (legal, institucional, social e economicamente) e como os atores interessados se inserem nessa seara. Não obstante, envolve compreender como essa rede de atores e contextos reflete na gestão do risco, e nas consequentes decisões tomadas sobre ele.

Atendo-nos ao âmbito nacional, que aqui nos interessa pelo caso da fosfoetanolamina, a governança envolve a definição de estruturas e processos para que, coletivamente, atores governamentais e não governamentais tomem decisões. Diante disso, está presente como elemento de governança a formação de redes, permitindo a ocorrência de acoplamentos através da construção de padrões comuns aceitos por diferentes estruturas. Conforme pondera Kjaer, ${ }^{45}$ trata-se de "[...]uma convergência de expectativas entre os atores envolvidos sobre um (mais ou menos desenvolvido) conjunto de princípios, normas e regras que constituem uma 'ordem superior'." Logicamente, acaba sendo constituída de modo horizontal, como um processo de descentralização decisória.

Contudo, apesar da estrutura horizontal formada pela governança, cada ator tende, internamente, a estruturar-se verticalmente, assim como preconizado na Teoria Burocrática de Weber, e sendo assim "[...] a capacidade de impor sanções negativas segue sendo reflexo da configuração interna dessas organizações [...]" ${ }^{\text {46 }}$. A gestão ainda continua a predominar no modo

\footnotetext{
${ }^{44}$ BERGER FILHO, Aírton Guilherme. Op. cit.

45 “[...] una convergencia de expectativas entre los actores en cuestión sobre la base de un (más o menos desarrollado) conjunto de principios, normas y reglas que constituyen un 'orden superior'" KJAER, Poul F. La metamorfosis de la síntesis funcional: una perspectiva europeo-continental sobre governance, derecho y lo político en el espacio transnacional. Tradução Francisco Mujica. Wisconsin Law Review, 2010, p. 169. Disponível em: <http://www.academia.edu/2105401/La_metamorfosis_de_la_s\%C3\%ADntesis_funcional._Una_perspectiva europeo-continental_sobre_governance_derecho_y_lo_pol\%C3\%ADtico_en_el_espacio_trasnacional>. Acesso em: 16 out. 2016.

46، [...] la capacidad de imponer sanciones negativas sigue deiniendo la forma de la coniguración interna de estas organizaciones". Ibidem, p. 168.
} 
como são tomadas as decisões, ou seja, as decisões são adotadas no nível mais baixo para impactar no nível mais elevado da governança, quando o oposto deveria imperar.

Como consequência da governança, há a gestão. Esta, por sua vez, a partir dos pressupostos estabelecidos horizontalmente na governança, constrói estruturas verticais. Ou seja, implementa e executa objetivos estabelecidos no âmbito da governança, sendo orientada por questões como “O que deve ser feito?”, “Como deve ser feito?”, “Em que momento deve ser feito?"

Alguns dos instrumentos pelos quais se concretiza a gestão no ordenamento jurídico brasileiro são licenciamento ambiental; estudo de impacto ambiental; zoneamento ambiental; desenvolvimento obrigatório de testes e procedimentos de notificação prévios à colocação de novos produtos no mercado; estabelecimento legal de valores limite para as emissões poluentes; proibição da atividade ou de lançamento de produto; embargos; notificações; monitorização; obrigações de registro; financiamento de ações de investigação, ou informação ao público; imposição de uma margem de segurança; imposição do uso da melhor tecnologia disponível.

Gestão sem governança significa desagregação dos atores e atuação descoordenada, pois cada um irá gerir - no presente caso, a precaução - de uma forma, perseguindo objetivos distintos. Foi desse mal que padeceu a fosfoetanolamina: cada órgão achou-se competente para julgar a matéria de forma unilateral e disfuncional, sem que fossem observados, discutidos, informados os reais riscos em jogo. Mesmo as existências de amparos legais sobre a matéria não foram capazes de assegurar a estabilidade e a assimetria na integração dos atores no caso da fosfoetanolamina. Aceitar um regime de exceção de competência de órgãos sanitaristas, como a Anvisa no Brasil, que já possui sua gestão precaucional, em relação aos pacientes terminais no caso de tratamentos experimentais, equivale a lhe retirar a autoridade sobre todas as outras drogas $^{47}$.

Falhas, para $\mathrm{Kjaer}^{48}$, decorrentes da falta de governança e que permitem a ocorrência do que o autor denomina de "clausura cognitiva". Por isso, o maior desafio para as organizações do Estado moderno, de acordo com o autor, se encontra justamente em construir essas pontes de coerência externa, mantendo a coerência interna.

Constata-se do exposto, e diante do caso da fosfoetanolamina, que a aplicação no Brasil do princípio da precaução se traduz apenas como um mecanismo de gestão, certamente

\footnotetext{
47 BARBOSA, Elina Magnan. Op. cit.

48 KJAER, Poul F. Op. cit.
} 
contribuindo ainda mais para as controvérsias existentes tanto sobre a aplicação desse princípio quanto sobre a própria fosfoetanolamina.

Implantar mecanismos de governança permite que a precaução não seja aplicada indiscriminadamente abrangendo ameaças ou suspeitas triviais; ou, ainda, que assuma caráter imperativo em suas medidas de implementação. O objetivo é evitar medidas invasivas e arbitrárias através de critérios que permitam maior eficácia à precaução. Logo, é necessário transcender a visão preto no branco que incide sobre a questão.

Mas a dúvida principal permanece: o que um tomador de decisão deve fazer com uma avaliação de risco que aponta para a incerteza? ${ }^{49}$ Tal operacionalização, para Aragão, ${ }^{50}$ parte, em um primeiro momento, à avaliação de quando se recorrer no caso concreto ao princípio da precaução. Envolve a avaliação de riscos, na qual se designa, na maioria das vezes em termos quantitativos, a intensidade e probabilidade de ocorrência de eventos indesejáveis, geralmente avaliados na seara científica. Empregam-se como parâmetros a amplitude que os riscos alcançam; o efeito retardativo que podem possuir, vez que sua manifestação pode ocorrer após muitas gerações, havendo implicações catastróficas pela escala exponencial; assim como a irreversibilidade de seus efeitos, ou ao menos o custo, para torná-los reversíveis.

Ainda assim permaneceria a dúvida sobre quão grave um risco deve ser para convocar a precaução. Para Aragão, ${ }^{51}$ o caminho seguro é através do respeito ao princípio da proporcionalidade, de modo que a decisão seja reflexo da "gravidade proporcional ao risco e à inaceitabilidade social do risco". Tais decisões, em função de a incerteza ser temporária na maior parte das vezes, acabam sendo de caráter provisório, incorrendo-se na necessidade de que sejam revistas periodicamente, abrindo espaço para procedimentos "flexíveis, participativos e interativos".

Por detrás desse processo gerencial, existe a governança sobre a matéria, definida sob a égide dos princípios da eficácia, da participação, da coerência, da transparência. Casos como o da fosfoetanolamina geralmente colocam os decisores no que Aragão ${ }^{52}$ denomina de "dilema paralisante", vez que, ao mesmo tempo em que apresentam grandes riscos, também apresentam grandes vantagens. 0 processo, neste caso, envolve a ponderação de vantagens e

\footnotetext{
49 STACEY, Jocelyn. Preventive Justice, the Precautionary Principle and the Rule of Law. In: ANANIANWELSH, ReFbecca et al. Regulating Preventive Justice. New York: Routledge, 2016. p. 23- 41. Disponível em: <https://ssrn.com/abstract=2772235>. Acesso em: 10 mai. 2017.

${ }^{50}$ ARAGÃO, Alexandra. Op. cit.

51 Ibidem, p. 29.

52 Ibidem, p. 38.
} 
inconvenientes, afastando-se do viés economicista e concentrando-se na pluridisciplinaridade, no contraditório e na transparência.

É nesse viés que o caso da fosfoetanolamina coloca o Estado em uma posição dúbia: ora impõe-se o dever de realizar um direito subjetivo, para os quais não há limites; ora impõe-se a obrigação jurídica de atuar dentro dos limites impostos pela segurança sanitária, estipulando regras para a produção, comercialização, prescrição e uso de medicamentos. Almeja-se que o Estado equilibre situações contraditórias, colocando-o entre o dever de impedir experimentações ilegais e, ao mesmo tempo, lidar com o desejo de indivíduos em tentar o possível e o impossível em sua busca por cura.

Ademais, a eficácia de um medicamento não está relacionada exclusivamente a sua capacidade de cura, mas também com a redução da dor, a melhoria da condição patológica ou, ainda, o prolongamento da vida. Todos os medicamentos possuem riscos, não isentos para todas as pessoas e em todas as circunstâncias. Sendo assim, o processo de liberação de medicamentos pela Anvisa já traz em seu bojo uma ponderação entre riscos e benefícios ${ }^{53}$.

Igualmente entendeu o Ministro Marco Aurélio no julgamento da medida cautelar da ADI 5.501: o direito à saúde não se concretiza sem a devida segurança oferecida pelo Estado quanto à qualidade das drogas. Ademais, compreendeu que o Congresso Nacional foi omisso em seu dever de tutelar a saúde da população ao permitir a distribuição de medicamento sem liberação pela Anvisa, tendo inclusive ferido o princípio da separação de poderes ao tomar para si competência deste órgão quanto à viabilização de distribuição de medicamentos ${ }^{54}$.

Aragão agrega a isso a construção social do risco e do nível adequado de proteção, o que implica na ampliação da participação pública, envolvendo todas as partes interessadas e afetadas de modo amplo e precoce. Destarte, a opinião “leiga” passa a galgar protagonismo. Neste mesmo sentido, Berger Filho ${ }^{55}$ defende que, para o alcance efetivo da governança, as decisões não sejam tomadas de portas fechadas, submetidas à guarda dos especialistas, exigindo-se transparência nos processos. Nesse sentido, Barbosa ${ }^{56}$ questiona: "Até que ponto se pode deixar ao juízo de um único médico, avalizado por um juiz, o recurso a terapias não permitidas? Qual a relação entre o direito a saúde e o direito a esperança?"

\footnotetext{
${ }^{53}$ BARBOSA, Elina Magnan. Op. cit.

${ }^{54}$ BRASIL. Superior Tribunal de Justiça. Medida Cautelar na Ação Direta de Inconstitucionalidade 5.501. Relator : Ministro Marco Aurélio. 19 de maio de 2016. Disponível em: <http://www.stf.jus.br/arquivo/cms/noticia NoticiaStf/anexo/adi5501MMA.pdf>. Acesso em: 05 abr. 2017.

${ }^{55}$ BERGER FILHO, Aírton Guilherme. Op. cit.

${ }^{56}$ BARBOSA, Elina Magnan. Op. cit.
} 
Enfatizam Gollier e Treich $^{57}$ que as discussões sobre o risco não dizem respeito apenas a peritos, políticos, juízes e empresários; são também de interesse da população. Os autores apontam que na Europa as agências reguladoras de risco perderam drasticamente a confiança dos cidadãos, que consideram a tomada de decisão elitista, sem qualquer consulta pública efetiva. A questão que entra em jogo neste caso é encontrar o instrumento certo para abertura participativa dos diversos atores.

A percepção social do risco é uma ponderação subjetiva, e como tal está sujeita a elementos agravantes (que vêm amplificar a percepção dos efeitos sobre riscos pouco graves ou prováveis) e atenuantes (que condicionam a aceitação de riscos muito graves e prováveis) de ordem qualitativa para a avaliação do risco, e que ainda serão condicionadas por aspectos subjetivos do indivíduo (preconceitos, preferências, etc.).

Não obstante, para se chegar ao nível adequado de proteção, que conceba a participação e incorpore assim a percepção social do risco de forma adequada, cabe avaliar os limites para aceitação deste último, pois "[...] pode acontecer que um risco elevado seja, mesmo assim, socialmente aceitável. E, o que também é frequente, pode acontecer o inverso - o risco ser baixo mas, mesmo assim, ser socialmente inaceitável". ${ }^{58}$ Portanto, a definição sobre o nível adequado de proteção reflete uma decisão ética e política, que incorpora as ponderações da comunidade científica, a tolerabilidade dos cidadãos e a aceitabilidade dos poderes políticos.

Gollier e Treich $^{59}$ fazem dois alertas importantes sobre a percepção social do risco e como isso impacta nas decisões políticas. De acordo com os autores, os consumidores percebem mal o risco que enfrentam, em função da ambiguidade do risco. Podem ocorrer escolhas exageradas em relação ao risco, especialmente quanto àqueles altamente divulgados, como se o pior cenário possível construído a partir de determinado risco fosse o mais provável; igualmente quando a possibilidade for positiva. Logo, no caso de alta incerteza científica, caberia ao governo um papel de intervenção, que se daria sobretudo através da informação e da educação.

Do outro lado, na classe legislativa, “[...] políticos com fortes preocupações de carreira podem optar pela política de risco que o público acredita ser bom em vez do que é realmente bom para o público. Isso é verdade em particular quando os riscos são de longo prazo, isto é, os

${ }^{57}$ GOLLIER, Christian; TREICH, Nicolas. Decision - Making Under Scientific Uncertainty: The Economics of the Precautionary Principle. The Journal of Risk and Uncertainty, v. 27, n. 1, p.77-103, 2003.

${ }^{58}$ ARAGÃO, Alexandra. Op. cit.

${ }^{59}$ GOLLIER, Christian; TREICH, Nicolas. Op. cit. 
riscos cujo resultado serão observados no futuro." ${ }^{60}$. Decisões assim afetam a maximização do bem-estar social.

No caso da fosfoetanolamina, o cenário não foi diferente: a falta de informações e educação sobre risco fez com que um contingente social considerável se posicionasse a favor da sua liberação, ressonado em decisões do Executivo, Legislativo e, de modo incipiente, no Judiciário. Na outra ponta, a oposição à FOS, especialmente por parte da Anvisa, era percebida, social e midiaticamente, como favorável aos interesses da indústria farmacêutica, vez que representaria uma ameaça a esta por ser de produção nacional e de baixo custo ${ }^{61}$.

Esses efeitos foram novamente verificados quando o consumo se tornou possível como suplemento alimentar. A legalização da fosfoetanolamina como suplemento alimentar já havia sido proposta pelo próprio ministro do MCTIC em 2016, à época, Celso Pansera. Novamente sob o fantasma de uma medida populista, a fim de que a população não estivesse sujeita a fontes clandestinas de acesso à substância ${ }^{62}$. Contudo, considerando que um suplemento alimentar não possui propriedades terapêuticas, parece-nos mais uma tentativa de burlar o sistema sanitário vigente.

Ainda que as recentes pesquisas apontem para a não toxidade da FOS no curto prazo, as incertezas continuam pairando sobre os efeitos de longo prazo, quanto à dosagem correta, assim como sobre seu efeito antitumoral. E o mais agravante é que ainda não há base científica para determiná-la como não prejudicial ao tratamento convencional de câncer.

Em nota à imprensa em 21 de fevereiro deste ano, a Anvisa informou que, até o momento, não houve nenhum pedido de registro na instituição, carecendo-se deste para a comercialização da substância no País. Contudo, a aquisição no exterior ou através de $e$ commerce estaria liberada para consumo pessoal. ${ }^{63}$

Atualmente, encontram-se suspensas as propagandas veiculadas pelo laboratório Quality Medical Line, nas quais havia a clara indução de consumo do suplemento como uma esperança

60 "[...] politicians with strong career concerns may prefer to select the risk policy that the public believes is good rather than the one which is actually good for the public. This is true in particular when long term risks, i.e., risks whose outcome will be observed in a distant future". Ibidem. p.98.

${ }^{61}$ NATURE. Op. cit.

62 CANSIAN, Natália. Ministério da Ciência, Tecnologia, Inovações e Comunicações. Ministro quer legalização da 'pílula do câncer' como suplemento alimentar. Folha de São Paulo, 2016. Disponível em: $<$ http://www1.folha.uol.com.br/equilibrioesaude/2016/03/1755566-ministro-quer-legalizacao-da-pilulado-cancer-como-suplemento-alimentar.shtml>. Acesso em: 15 jun. 2017.

${ }_{63}$ BRASIL. Agência Nacional de Vigilância Sanitária. Nota sobre fosfoetanolamina como "suplemento alimentar". 2017b. Disponível em: <http://portal.anvisa.gov.br/noticias//asset_publisher/FXrpx9qY7FbU/content/nota-sobre-fosfoetanolamina-como-suplemento-alimentar>. Acesso em 20 jun. 2017. 
de cura ao câncer. Ao final de março deste ano, o Instituto do Câncer do Estado de São Paulo (Icesp), responsável pela realização da segunda fase de testes da FOS, divulgou através de seu diretor geral, Paulo Hoff, que a substância havia sido eficaz apenas no tratamento de melanoma em um dos 72 pacientes estudados entre 10 tipos de câncer ${ }^{64}$.

Tais fatos novamente corroboram para evidenciar, de um lado, que a precaução era o melhor caminho a ter sido tomado como medida cautelar; de outro, como a questão se sujeita a deslindes como estes em função de a matéria apenas ser gerida e não governada. Da aplicação das medidas precaucionais, dentro da governança proposta, possibilita-se a maior conscientização social do risco, o que, de um lado, implica que a sociedade esteja melhor preparada no caso de o risco se concretizar, inclusive minorando a repercussão dos efeitos, e, de outro, eleva o bem-estar social pelo aumento da confiança.

Neste ponto, entra em debate o cerne do presente artigo: como, em situações semelhantes à apresentada e outras - aquelas na seara ambiental por exemplo -, se pode avançar em instrumentos de governança, em vez de ficarmos presos aos instrumentos de gestão praticados individualmente por cada órgão, instituição e continuarmos à mercê dos caprichos legislativos e executivos?

As mudanças na avaliação do risco a partir da precaução tornam-se complexas, especialmente pela força exercida para a manutenção do status quo ${ }^{65}$. Isso é significativamente importante por corroborar que os atuais instrumentos de gestão são insuficientes, reiterando a necessidade de governança sobre a questão.

\section{CONCLUSÃO}

Assim como em outros ramos do direito, a saúde também vem impondo novos direitos e correspondentes obrigações, em especial por parte do Estado, em sua promoção e salvaguarda. A precaução atua nesses casos garantindo que esses direitos serão atendidos de modo seguro e eficaz.

Conforme o panorama esboçado, reconhecemos que o artigo embora apresente possibilidades de como esse corpo teórico pode tomar forma instaurando um protocolo e uma

\footnotetext{
${ }^{64}$ USP. Estudo no Icesp sugere que fosfoetanolamina não é eficiente contra o câncer. Jornal da USP, 2017. Disponível em: <http://jornal.usp.br/ciencias/ciencias-da-saude/estudo-no-icesp-sugere-quefosfoetanolamina-nao-e-eficiente-contra-o-cancer/>. Acesso em: 15 jun. 2017.

${ }^{65}$ STACEY, Jocelyn. Op. cit.
} 
abertura de decisão pelo próprio Direito, não oferece uma resposta concreta de ferramentas para sua viabilização prática na medida necessária. O processo de governança é complexo, e exige articulação entre os atores interessados e, sobretudo, a abertura para participação. São mecanismos de implantação que precisam ser criados a apropriados por cada sociedade, se adequando a cada realidade fática.

Verifica-se na ordem atual a concentração nos pressupostos de gestão da precaução, o que reflete como o recurso à precaução acaba sendo difuso e descoordenado nos diversos âmbitos públicos em que é empregada, corroborando para que se propague um discurso desfavorável pela dicotomia existente entre uma "precaução forte" e uma "precaução fraca", ${ }^{66}$ que definem os parâmetros de aceitabilidade sobre os riscos da incerteza. Nesse sentido, estabelecer processos de governança são fundamentais para coordenar a aplicação do princípio, e enfim, retirá-lo da ambiguidade e inefetividade propalada jurídica e doutrinariamente.

Não obstante, revelam-se ricas as considerações apresentadas diante do precedente aberto pela fosfoetanolamina, assim como outros são recorrentemente abertos em outras searas. No campo da saúde são urgentes essas questões, em especial, pela reprodução da situação em apreço. Em caso semelhante, medicamentos inibidores de apetite foram suspensos pela Anvisa pela constatação de efeitos colaterais sérios e falta de comprovação científica quanto a sua eficácia e segurança, em seguida Legislativo e Executivo liberam determinadas substâncias através da Lei n. 13.454 de 23 de junho de 2017, ${ }^{67}$ atravessando a competência da Anvisa como órgão regulador. Novamente o Brasil é colocado em situação vexatória no âmbito internacional pela falta de governança sobre a matéria que claramente deveria ser orientada pela precaução.

Mais uma evidência da urgência da mudança de paradigma gerencial para governança. Cabe recordarmos, que com os diversos avanços científicos, ao mesmo tempo em que algumas incertezas são dissipadas, tantas outras nascem. Cenário especialmente vivenciado no campo da saúde, vez que a busca por curas, maior qualidade de vida, maior tempo de vida são eternamente prosseguidas e instigam muitas emoções.

\footnotetext{
${ }^{66}$ Termos teóricos aplicados por Sustein para definição do grau de aplicação do princípio. SUSTEIN, Cass R. Para além do princípio da precaução. Revista de Direito Administrativo, Rio de Janeiro, v. 259, p. 11-71, abr. $2012 . \quad$ Trimestral. Disponível em: <http://bibliotecadigital.fgv.br/ojs/index.php/rda/article/view/8629>. Acesso em: 5 out. 2016.

${ }^{67}$ BRASIL. Lei n. 13.454, de 23 de junho de 2017. Autoriza a produção, a comercialização e o consumo, sob prescrição médica, dos anorexígenos sibutramina, anfepramona, femproporex e mazindol. In: Diário Oficial da República Federativa do Brasil, Brasília, DF, 26 jun. 2017c. Disponível em: <http://www.planalto.gov.br/ccivil_03/_ato2015-2018/2017/lei/L13454.htm>. Acesso em: 10 jul. 2016.
} 
Assim, à medida que crescem os estudos nessa área mais opções terapêuticas são criadas, testadas, liberadas. E como tal, mais medidas precaucionais devem ser estabelecidas, a fim de evitar que as mesmas emoções que possibilitam a criação de medicamentos sejam orientadoras de sua liberação a qualquer preço, inclusive se este preço envolver a vida e a saúde de milhares de indivíduos.

O caso da fosfoetanolamina, assim como outros medicamentos, como visto no caso da Itália e dos Estados Unidos, e também no Brasil, somado ainda a tantas outras curas do tipo milagrosa, demonstra o cuidado necessário sobre a questão, evidenciando como as frentes decisórias poderiam ter sido diferentes caso a precaução fosse orientadora dentro de um processo de governança.

Permanecer gerindo a precaução equivale a insistir em deixamos um princípio jurídico consagrado, e de suma importância para a tomada de decisão em ambientes de incerteza cientifica, à deriva. É ainda, insistir sobre a cegueira dos efeitos dessas decisões, e que assim, permaneçamos capturados pela incerteza ao invés de decidirmos sobre ela.

\section{REFERÊNCIAS}

ALVES, Sandra Mara Campos; DELDUQUE, Maria Célia; SANTOS, Alethele Oliveira. Lei n. 13.269/2016: a comoção da sociedade vence o método científico. Cadernos de Saúde Pública, Rio de Janeiro, v. 32, n. 6, p. 1-2, 2016. Disponível em:

http: //www.scielo.br/pdf/csp/v32n6/1678-4464-csp-32-06-e00070116.pdf. Acesso em: $01 \mathrm{abr}$. 2017.

ARAGÃO, Alexandra. Princípio da precaução: manual de instruções. Revista do Centro de Estudos de Direito do Ordenamento, do Urbanismo e do Ambiente, Coimbra, n. 22, p. 9-57, 2008. Disponível em: https://digitalis.uc.pt/pt-pt/node/106201?hdl=8833. Acesso em: 5 out. 2016.

BARBOSA, Elina Magnan. Right to try? Fosfoetanolamina, di Bella e Stamina: uma análise ítalobrasileira. Revista de Direito Sanitário, São Paulo, v. 17, n. 2, p. 66-92, jul./out. 2016. Disponível em: http://www.revistas.usp.br/rdisan/article/view/122307. Acesso em: 20 abr. 2017.

BERGER FILHO, Aírton Guilherme. A governança dos riscos das nanotecnologias e o princípio da precaução: um estudo a partir da teoria dialética da rede. 2016. 438 f. Tese (Doutorado em Direito) - Universidade do Vale do Rio dos Sinos, São Leopoldo, 2016.

BRASIL. Agência Nacional de Vigilância Sanitária. Nota sobre fosfoetanolamina como "suplemento alimentar". 2017b. Disponível em: http://portal.anvisa.gov.br/noticias/- 
/asset_publisher/FXrpx9qY7FbU/content/nota-sobre-fosfoetanolamina-como-suplementoalimentar. Acesso em 20 jun. 2017.

BRASIL. Agência Nacional de Vigilância Sanitária. Resolução n. 38, de 12 de agosto de 2013. Aprova o regulamento para os programas de acesso expandido, uso compassivo e fornecimento de medicamento pós-estudo. Disponível em: < http://bvsms.saude.gov.br/bvs/saudelegis/anvisa/2013/rdc0038_12_08_2013.html>. Acesso em 20 abr. 2017.

BRASIL. Câmara dos Deputados. Projeto de Lei n. ${ }^{\circ} 3.454$, de 2015. Dispõe sobre a fabricação, produção e distribuição da Fosfoetanolamina Sintética aos pacientes com câncer. Disponível em: http://www.camara.gov.br/sileg/integras/1410290.pdf. Acesso em: 01 jun. 2017.

BRASIL. Lei n._6.360, de 23 de setembro de 1976. Dispõe sobre a vigilância sanitária a que ficam sujeitos os medicamentos, as drogas, os insumos farmacêuticos e correlatos, cosméticos, saneantes e outros produtos, e dá outras providências. In: Diário Oficial da República Federativa do Brasil, Brasília, DF, 24 set. 1976. Disponível em: http://www.planalto.gov.br/ccivil_03/leis/16360.htm. Acesso em: 15 abr. 2016.

BRASIL. Lei n. 13.454, de 23 de junho de 2017. Autoriza a produção, a comercialização e o consumo, sob prescrição médica, dos anorexígenos sibutramina, anfepramona, femproporex e mazindol. In: Diário Oficial da República Federativa do Brasil, Brasília, DF, 26 jun. 2017c. Disponível em: http://www.planalto.gov.br/ccivil_03/_ato2015-2018/2017/lei/L13454.htm. Acesso em: 10 jul. 2016.

BRASIL. Ministério da Ciência, Tecnologia, Inovações e Comunicações. MCTI anuncia plano de trabalho para as pesquisas sobre a fosfoetanolamina. 2015. Disponível em:

http://www.mctic.gov.br/mctic/opencms/salalmprensa/noticias/arquivos/migracao/2015/11/M CTI_anuncia_plano_de_trabalho_para_as_pesquisas_sobre_a_fosfoetanolamina.html. Acesso em 25 abr. 2017.

BRASIL. Superior Tribunal de Justiça. Medida Cautelar na Ação Direta de Inconstitucionalidade 5.501. Relator : Ministro Marco Aurélio. 19 de maio de 2016. Disponível em: http://www.stf.jus.br/arquivo/cms/noticia NoticiaStf/anexo/adi5501MMA.pdf. Acesso em: 05 abr. 2017.

BOURDIEU, Pierre. O Campo científico. In: ORTIZ, Renato. Bourdieu: Sociologia. São Paulo: Ática, 1983.

CANSIAN, Natália. Ministério da Ciência, Tecnologia, Inovações e Comunicações. Ministro quer legalização da 'pílula do câncer' como suplemento alimentar. Folha de São Paulo, 2016. Disponível em: http://www1.folha.uol.com.br/equilibrioesaude/2016/03/1755566-ministroquer-legalizacao-da-pilula-do-cancer-como-suplemento-alimentar.shtml. Acesso em: 15 jun. 2017.

CANSIAN, Natalia; WATANABE, Phillippe; LOPES, Reinaldo José. "Pílula do Câncer" vira suplemento, e Anvisa investigará se há infração. Folha de São Paulo, 2017. Disponível em: http://www1.folha.uol.com.br/equilibrioesaude/2017/02/1859504-pilula-do-cancer-virasuplemento-e-anvisa-investigara-se-ha-infracao.shtml. Acesso em: 16 maio 2017. 
PARDO, José Esteve. 0 desconcerto do Leviatã: política e direito perante as incertezas da ciência. 3. v. São Paulo: Inst. O Direito por um Planeta Verde, 2015. (Direito ambiental para o século XXI).

GOLLIER, Christian; TREICH, Nicolas. Decision - Making Under Scientific Uncertainty: The Economics of the Precautionary Principle. The Journal of Risk and Uncertainty, v. 27, n. 1, p.77-103, 2003.

GOMES, Carla Amado. Risco e Modificação do Acto Autorizativo Concretizador de Deveres de Protecção do Ambiente. 2007. 566 f. Tese (Doutorado em Direito Administrativo) - Universidade de Lisboa, Lisboa, 2007.

KJAER, Poul F. La metamorfosis de la síntesis funcional: una perspectiva europeo-continental sobre governance, derecho y lo político en el espacio transnacional. Tradução Francisco Mujica. Wisconsin Law Review, p. 153-204, 2010. Disponível em:

http://www.academia.edu/2105401/La_metamorfosis_de_la_s\%C3\%ADntesis_funcional._Una_pe rspectiva_europeo-

continental_sobre_governance_derecho_y_lo_pol\%C3\%ADtico_en_el_espacio_trasnacional.

Acesso em: 16 out. 2016.

NATURE. Drugs on demand: controversy in Brazil over access to a purported cancer cure could set a harmful precedent. Nature, v. 527, p. 410, 2015. Disponível em: < https://www.nature.com/news/drugs-on-demand-1.18873>. Acesso em 27 abr. 2018.

RÊGO, Juliana Florinda M.; LOPES, Gilberto; RIECHELMANN, Rachel P.; STENBERG, Cinthya; FERRARI, Claudio; FERNANDES, Gustavo. A "miracle" câncer drug in the era of social media: a survey of Brazilian oncologists' opinions and experience with phosphoethnolamine. Rev. Assoc. Med. Bras., São Paulo, v. 63, n. 1, p. 70-77, 2017.Disponível em:

http: / / www.scielo.br/scielo.php?script=sci_arttext\&pid=S0104-42302017000100070. Acesso em 05 abr. 2017.

STACEY, Jocelyn. Preventive Justice, the Precautionary Principle and the Rule of Law. In: ANANIAN-WELSH, ReFbecca et al. Regulating Preventive Justice. New York: Routledge, 2016. p. 23- 41. Disponível em: https://ssrn.com/abstract=2772235. Acesso em: 10 mai. 2017.

SUSTEIN, Cass R. Para além do princípio da precaução. Revista de Direito Administrativo, Rio de Janeiro, v. 259, p. 11-71, abr. 2012. Trimestral. Disponível em:

http://bibliotecadigital.fgv.br/ojs/index.php/rda/article/view/8629. Acesso em: 5 out. 2016.

TEODORO, Cristiane Roberta dos Santos; CAETANO, Rosângela. O caso da fosfoetanolamina sintética e a preocupante flexibilização das normas sanitárias no Brasil. Physis Revista de Saúde Coletiva, Rio de Janeiro, v. 26, n. 3, p. 741-746, 2016. Disponível em:

http: //www.scielo.br/scielo.php?script=sci_arttext\&pid=S0103-73312016000300741. Acesso em: 20 abr. 2017.

WEBER, Max. Economia e Sociedade. V. 1. Brasília: UNB, 2004. 
USP. Estudo no Icesp sugere que fosfoetanolamina não é eficiente contra o câncer. Jornal da USP, 2017. Disponível em: http://jornal.usp.br/ciencias/ciencias-da-saude/estudo-no-icespsugere-que-fosfoetanolamina-nao-e-eficiente-contra-o-cancer/. Acesso em: 15 jun. 2017.

Recebido em: 23.07.2017 / Revisões requeridas em: 15.09.2017 / Aprovado em: 27.09.2017 / Publicado em: 05.05.2018

\section{COMO FAZER A REFERÊNCIA DO ARTIGO (ABNT):}

JUNG, Patricia, RENK, Arlene Anélia. Capturados pela incerteza: as lições do caso da "pílula do câncer" para a precaução. Revista Eletrônica do Curso de Direito da UFSM, Santa Maria, RS, v. 13, n. 1, p. 159-182, abr. 2018. ISSN 1981-3694. Disponível em: < https://periodicos.ufsm.br/revistadireito/article/view/28231 >. Acesso em: dia mês. ano. doi: http://dx.doi.org/10.5902/1981369428231 . 